ПОСУХОВА Оксана Юрьевна - кандидат социологических наук, доцент; доцент кафедры регионалистики и евразийских исследований Института социологии и регионоведения Южного федерального университета (344006, Россия, г. Ростов-на-Дону, ул. Пушкинская, 160; belloks@ yandex.ru)

ЧЕЛЫШЕВ Сергей Михайлович - стажер-исследователь Института социологии и регионоведения Южного федерального университета (344006, Россия, г. Ростов-на-Дону, ул. Пушкинская, 160; msyeserj@mail.ru)

\title{
ДИНАСТИЙНОСТЬ И ФРЕЙМЫ СОВЕТСКОГО КИНОДИСКУРСА
}

\begin{abstract}
Аннотация. Статья посвящена рассмотрению институциональных условий репрезентации профессиональных династий в кинодискурсе и анализу содержательной трансформации советского кинодискурса о профессиональных династиях. Авторы выделяют фреймы советского кинематографа (диагностический, мотивационный, прогностический) и дают их содержательные категории. Обозначение содержательных категорий фреймов позволило зафиксировать более выраженную позитивность коннотаций фреймов в репрезентации династий рабочих и героических профессий (военные, милиция), в то время как династийность нерабочих профессий имеет нейтральные или негативные коннотации.
\end{abstract}

Ключевые слова: династии, профессия, фрейм, кинодискурс, советский кинематограф

$\mathrm{K}$ ино, являясь одним из видов синтетического искусства, в СССР, как и в других странах, рассчитан на массовую аудиторию. С одной стороны, одной из важнейших социальных функций кино является развлечение, с другой - трансляция нормативных моделей поведения. Поэтому киноповестка Советского Союза подчинялась определенным правилам формирования и была обусловлена спецификой исторического этапа развития страны - «политика и экономика буквально сращиваются с советским кино» [Храмов 2009: 185]. Бюджет отдельного фильма и всего кинопроизводства, творческая идея обсуждались и утверждались на разных уровнях власти, в т. ч. и правительственном. Кинопроизводство было реально включено в процесс «социалистического строительства», было обусловлено государственным заказом, транслируя нормативное должное и легитимируя уже достигнутое.

Особое место в советском кинематографе занимало производственное кино, которое не только отражало реальную ситуацию в производственной сфере, в развитии производственных коллективов, но и транслировало государственный заказ на формирование нового типа личности - «советского человека».

В данной статье предметом исследования является интерпретация презентаций профессиональных династий в советском кинодискурсе. Это обусловлено тем, что многопоколенные семьи, работающие на одном производстве, приобретают «особый статус на цеховом и заводском уровнях. Рабочая династия презентуется как один из социально одобряемых, публично озвученных типов семейной организации» [Ткач 2003]. Однако ситуация меняется, если речь идет о династиях в интеллигентных профессиях, что хорошо прослеживается с конца 70-х гг. XX в.

Структурными элементами статьи выступают институциональные условия репрезентации профессиональных династий в кинодискурсе и дискурсы о профессиональных династиях, их содержательной трансформации.

Методология исследования. Согласно конструктивистскому подходу, социальная проблема - это продукт процесса коллективного определения [Hilgatner, 
Bosk 1988]. Важную роль в актуализации или выдвижении той или иной социальной проблемы в СМИ играют интересы акторов, обусловливающие появление определенной социальной проблемы в публичном дискурсе. По мнению С. Хилгатнера и К. Боска, социальные проблемы соревнуются между собой за общественное внимание на аренах публичного дискурса [Hilgatner, Bosk 1988: 55]. «Публичные арены» включают органы власти, СМИ, научные организации и частные фонды. На этих аренах происходит обсуждение, интерпретация, отбор и презентация проблем для общественности. Число социальных проблем, которые арена может принять одновременно, ограничено. Поэтому те проблемы, которые прошли такой отбор, являются важными в процессе коллективного самоопределения [Гольбрайх 2013: 65].

Кино можно рассматривать как одну из публичных арен, на которой аудиовизуальными средствами презентируется определенная социальная проблема. Для анализа советского кинодискурса можно использовать анализ фреймов, позволяющий выявить особенности и технологии подачи информации в кино и ее воздействия на аудиторию, суть которого выражена в следующем: «реальность - не то, о чем говорят, а то, как говорят» [Актуальные вопросы... 2017: 45; Scheufele, Tewksbury 2007]. Фрейминг - это «процесс конструирования источником информации какой-либо социальной или политической проблемы для своей аудитории» [Nelson, Oxley, Clawson 1997]. Для советской действительности верным представляется и концепция Маршалла Маклюэна, сформулированная им в его знаменитом высказывании: «Medium is the message». Согласно концепции Маклюэна, чтобы коммуникация была успешной, надо чтобы адресат был знаком со средством коммуникации, используемым для передачи информации, мог его раскодировать, понять смысл высказывания, при этом учитывая контекст, особенности средства коммуникации. По этой причине кинематограф для широких слоев трудящихся как целевой аудитории советского государства представлялся наиболее перспективной формой коммуникации. Художественные средства трансляции посылов не требовали от аудитории никакой специальной подготовки, обладали яркостью и доступностью вложенных смыслов и прикрывались яркой игрой актеров. Выход фильма в кинопрокат либо его демонстрация на каналах государственного телевидения обеспечивали высокую степень уверенности в том, что месседж дойдет до широких слоев и будет воспринят ими в соответствии с целями и задачами производства.

Кинодискурс представляет собой систему смыслов и значений, которые иначе можно назвать фреймами (идеологическими рамками), посредством которых происходит легитимация или делигитимация общественного порядка [Здравомыслова, Темкина 2002: 434]. При анализе кинофреймов использована концепция Д. Сноу и Р. Бенфорда, в которой выделяется три центральных фрейма: диагностический, прогностический и мотивационный. Мотивационный фрейм - артикуляция обоснования участия в деятельности по устранению проблемы; диагностический фрейм относится к идентификации проблемы, атрибуции ответственных за проблему, причинам проблемы, т.е. осуществляет определение проблемы; прогностический предполагает решение проблемы, включая стратегию, тактику и цели, фокусировку на том, как реальность должна быть изменена и что надо сделать, чтобы ее изменить [Гольбрайх 2013: 71].

Эмпирической базой исследования выступили 7 советских кинофильмов, в которых присутствует в разной степени явление династийности («Большая семья» (реж. И. Хейфиц, 1954); «Добровольцы» (реж. Ю. Егоров, 1958); «Офицеры» (реж. В. Рогов, 1971); «Здравствуйте, доктор!» (реж. В. Левин, 
1974); «Гараж» (реж. Э. Рязанов, 1979); сериал «Государственная граница» (реж. Б. Степанов, 1980-1988 гг.); сериал «Рожденная революцией» (реж. Г. Кохан, 1974-1978).

\section{Институциональные условия репрезентации профессиональных династий в кинодискурсе}

Дискурс семейственности и династийности в советском обществе был неоднозначным. Сам факт династийности в первую очередь характерен для сословного типа общества. При главенствующем классовом подходе существование династий невозможно, с одной стороны, в силу идеологических причин (слом старого порядка: «кто был никем, тот станет всем»), с другой - в силу образовательной политики (борьба с безграмотностью, когда решающую роль в жизненных траекториях уже играют не материальные возможности семьи, а «исключительно способности и подготовка ребенка» [Макаренко]). Уже в первые пятилетки появилось представление о рабочем классе как ведущей силе советского общества, где многопоколенная рабочая семья, представители каждого поколения которой работают на одном предприятии, приобретает особый статус. Рабочая династия презентируется как один из социально одобряемых, публично озвученных типов семейной организации [Ткач 2003]. При том, что семейственность и династийность в других профессиях не приветствуется, рабочая династия получает новое звучание и обретает свою ценность. Ценность рабочих династий обусловливается особенностями трансмиссии социального статуса: преемственность, опыт отца передается сыну, а от него - последующим поколениям, продолжая семейные традиции в производственной сфере, что также актуализировало вопрос о формировании потомственных рабочих. Происходит осознание династийности как основы стабильности и устойчивого развития советского общества.

В 60 -х гг. рабочие династии утрачивают свою престижность. Их продолжают поддерживать, пропагандировать опыт, семейственность, но уже меняются представления людей об успешности в жизни. И эта успешность уже связана не с рабочими династиями, а с получением образования. Образование становится важным каналом для социальной мобильности, а ориентация на получение высшего образования фактически становится нормативной моделью поведения советской молодежи [Социальная мобильность... 2017: 64-65]. В этот период во «взрослую жизнь» вступает уже второе поколение, рожденное в советском обществе, фиксируются изменения в социальной структуре общества [Горшков 2011: 160], а также положительные изменения в правовом положении индустриальных рабочих ${ }^{1}$.

Однако эти положительные изменения способствовали не только приросту рабочего класса за счет миграции крестьян в город, но и оттоку из рабочего класса молодежи в интеллигенцию в результате доступности образования и вертикальной мобильности [Терентьев 2003: 29-30]. В этих условиях рабочие династии презентируются как хранители заводских традиций, как гарант возврата на завод после высшего образования с работой по полученной квалификации. Поэтому важная роль рабочих династий в социалистическом строительстве озвучивается и на государственном уровне. «И очень важно, что <... кадровые рабочие, потомственные трудовые семьи проявляют отеческую заботу о достойной смене, помогают ей овладевать мастерством, приобретать необходимый опыт» [Черняева, Сорокина 2019].

1 Русская сословная пенсия: дошло до колхозников. - Коммерсантъ Деньги. 2017. № 12. 01.04.2017. Доступ: https://www.kommersant.ru/doc/3249273 (проверено 19.10.2021). 
Динамичные изменения в социальной структуре советского общества, а также позитивные изменения образа жизни советского человека, профессиональные и трудовые достижения находили отражение в ведущих СМИ СССР. Ввиду того, что рабочие династии, семейная преемственность в труде артикулируются как важная государственная задача, в центральных газетах «Правда» и «Известия» появляются ряд публикаций с положительной коннотацией освещения данного вопроса: «почетом пользуются на уральском заводе рабочие династии - семьи, представители которых наследуют отцовское ремесло из поколения в поколение, сохраняют верность своему предприятию» 1 ; «партком совхоза "Приокский" Луховицкого района решил создать на центральной усадьбе хозяйства галерею династии Нартовых. Три члена этой семьи потомственных животноводов удостоены звания Героя Социалистического Труда. Нартовы награждены семью орденами Ленина» ${ }^{2}$. Однако необходимо отметить, что объектами журналистского интереса в основном были представители рабочих и крестьянских династий, династии представителей высококвалифицированного умственного труда не заполняли новостную повестку, за исключением представителей «героических» профессий (например, военных) [Черняева, Сорокина 2019].

Изменения затрагивают не только социальную структуру, но и кинематограф как важнейшую «арену» трансляции важных социальных проблем. С конца 1960-х гг., наряду с запретом ряда фильмов, сценаристов и режиссеров вынуждают работать по указке цензоров. Сложившаяся ситуация возникла в результате запроса советской политической системы на укрепление идеологической ситуации в стране, что нашло отражение в ряде нормативных документов, регулирующих деятельность в сфере культуры и искусства [Федоров 2016: 31-44].

Кинематограф СССР транслировал актуальную для государства повестку дня. В силу его аудио- и визуальной презентабельности он оказывал большое воздействие на восприятие транслируемой информации. Особенность данной информации заключалась в том, что она была представлена в виде законченных сюжетов, вписанных в повседневные жизненные ситуации советского человека, демонстрируемых на большом экране.

Таким образом, сложившиеся условия трансформации социальной структуры, призывы через СМИ от первых лиц государства к воспроизводству трудовых династий, усиления контроля над кинематографом сказывались на киноповестке СССР и в зависимости от выбора профессиональной группы на разных этапах меняли комплиментарность и эмоциональную окраску в контексте репрезентаций профессиональных династий в СССР.

\section{Фреймы советского кинематографа и репрезентация профессиональных династий}

Диагностический фрейм. Анализ массива советских фильмов позволяет выделить следующие типы диагностических фреймов, характерные для советского кинематографа (преимущественно для фильмов на производственную тематику) в различные временные этапы.

1. Проблема «личное vs общественное». Реализуется через противопоставление личной жизни героя фильма его общественной трудовой деятельности, проблематику выбора между семьей и производством, трудовой деятельностью. Примерами фильмов с такой проблематикой служат фильмы «Большая семья» (реж. И. Хейфиц, 1954), «Офицеры» (реж. В. Роговой, 1971). Как пра-

\footnotetext{
1 Сила личного примера. - Известия. 1976. № 143. С. 2.
}

2 Правда. 1968. 16 марта. С. 1. 
вило, создатели склоняются к тому, что производство, профессия как долг Родине в итоге становятся важнее семьи, и герои это потом понимают и меняют свое отношение. В качестве примера можно привести монолог Любаши, жены Алексея Трофимова («Офицеры», число просмотров - 53,4 млн зрителей ${ }^{1}$ ), после возращения мужа из очередного опасного военного задания: «Устала я Алексей, понимаешь, устала. Всю жизнь я только и делала, что ждала. Ждала, когда ты дрался <... я только и делала что ждала. И дождалась. Вечером ты приезжаешь, а утром заявляешь: собирайся! Куда собираться, Алексей?! Хватит, мне надоела казенная мебель с инвентарными номерами. Я в Москву хочу, понимаешь? В Москву, я там родилась... Подумай о сыне... И я тоже человек, Алексей! Мне нужно наконец закончить институт». Но весь ее монолог обрывается и мнение меняется, когда она видит новые ранения мужа, и как медик она понимает, что он чудом остался жив при выполнении очередного задания. Сцена заканчивается диалогом: «Когда едем, Алеша? Послезавтра, Любаша» (55:46). Как офицерская жена она будет следовать за мужем, и даже когда им представится возможность переехать в Москву, именно она примет решение об отказе, понимая, насколько мужу дорога нынешняя дивизия, и особую ценность для их семьи имеет еще и потому, что в ней служил их погибший на Великой Отечественной войне сын Егор.

2. «Династийность и непотизм». В 50-60-е гг. династийность презентируется как достойный пример для подражания (см. мотивационные фреймы), а в 70-80-е гг. проблематика династийности в отечественном кинематографе, как правило, демонстрировалась в негативном разрезе, при котором основными последствиями династийности становились протекционизм и непотизм. Традиционным становится сюжет, при котором герой сталкивается с тем, что продвижение по социальной и профессиональной лестнице для него закрыто ввиду наличия так называемых блатных - детей высшего начальства. Система в результате этого закрывается, каналы мобильности функционируют менее эффективно. Продвижение «сына товарища Милосердова» или получение им социальной выгоды, обусловленные одним только фактом принадлежности к семье руководящего работника и не подтвержденные уровнем профессионализма, преподносится как беда («Гараж», 28,5 млн зрителей $)^{2}$.

По сюжету фильма идет собрание членов гаражного кооператива «Фауна» (32 пайщика), где решаются текущие проблемы стройки. «Большую помощь оказал нам лично товарищ Милосердов. Мы снова попали в план сдачи объекта этим годом» (Сидорин, 1:4:02). Однако необходимо сократить число пайщиков на 4 человека. В момент голосования один из кандидатов на исключение поднимает вопрос, что в списке пайщиков на получение гаража появился какой-то Милосердов, сын большого начальника, за которого никто не голосовал. По фильму сын товарища Милосердова предстает ухоженным и модно одетым молодым человеком. «Но я же не виноват, что я его сын. Родителей не выбирают, хотя я лично своими доволен» (сын Милосердова, 1:21:39). Показательная сцена попытки знакомства сына Милосердова с рядом сидящей молодой женщиной: «А вас как зовут? - Марина. Только не называйте своего имени, вы для меня навсегда останетесь сыном товарища Милосердова. В этом романтика нашего времени» (Марина, 1:21:49). За весь фильм ни разу не упоминается имя сына товарища Милосердова, его идентичность определяется только принадлежностью к семье - семейному бренду Миросердовых.

\footnotetext{
1 Офицеры. Доступ: https://www.kinopoisk.ru/film/42736/ (проверено 19.10.2021).
}

2 Гараж. Доступ: https://www.kinopoisk.ru/film/44467/ (проверено 19.10.2021). 
Еще одна сюжетная линия переживания Марины, что на одну семью (она и ее отец - член-корреспондент АН СССР) два гаража не дадут, и они могут оказаться в списке исключенных, поэтому она не дает отцу Павлу Константиновичу Смирновскому выступить в поддержку несправедливости ранее озвученного списка: «И не лезь в драку, у нас у самих рыло в пуху» (Марина, 1:23:53), и в принципе отец согласен с ней: «Надо было и мне голосовать против, не было бы так мерзко, но испугался, два гаража на одну семью» (Смирновский, 1:30:54).

Очень интересна сцена разговора Марины, дочки члена-корреспондента АН СССР, и сына товарища Милосердова, начиная с ситуации о том, что они могут первыми пострадать как принадлежащие к династиям, в которой четко прослеживается негативное отношение к династиям на данном историческом отрезке времени, с одной стороны, и предопределенность жизненных траекторий детей из высокоресурсных династий - с другой: «Между прочим, нас с вами в этих джунглях могут съесть в любую минуту... А про вас все ясно, закончили Институт международных отношений. - Ну, вы мне льстите... Ну, вы идете по стандарту, раз сын товарища Милеросердова, значит что-то очень модное. Неужели вы слесарь? - Нет, это чересчур. Я археолог.. Ну а вы, дочка профессора, кто? - У меня все по штампу. Нормально. Закончила факультет филологический в МГУ» (Марина, 1:52:46).

Заседание правления в фильме заканчивается идеализированной сценой исключением сына товарища Милосердова и дочки члена-корреспондента АН СССР из первой очереди на получение гаража: «Давайте избавимся от блатных, и в первую очередь от сына товарища Милосердова» (Малаева, 1:18:13), «третья, я думаю, дочка Смирновского, хватит им на семью одного гаража» (Аникеева, 1:22:35).

Мотивационный фрейм. В соответствии с целями и задачами, как правило, спускавшимися перед создателями фильмов на производственную тематику, в контексте разреза династийности можно выделить такой тип мотивационного фрейма, как гордость за свой труд и продолжение семейной династийной традиции. Наиболее ярко это показано в фильме «Большая семья» $(26$ млн зрителей $)^{1}$. Данный фрейм, преподносящийся через одобрение старшими членами семьи деятельности представителей младшего поколения, призван формировать у зрителя стремление к подражанию курсу деятельности главных героев: «12 кораблей на моем веку, а помню название каждого, помню год, когда его на воду спускали, помню, как дни рождения своих детей» (Агафья Карповна, 1:36:23). Для достижения данной цели характерно то, что герои, как правило, не показаны идеальными людьми без недостатков (пример - в сцене «образцовый завтрак стахановца», после фотографии в журнале Алексея Журбина и посещения его отцом, Ильей Журбиным, и другом семьи Басмановым: «Рабочая слава она не на голом месте растет... ее не в одиночку, ее сообща выращивают» (Басманов, 41:10). Как это было характерно и для фильмов сталинской эпохи, зрителю демонстрируется «обычность» таких героев, предоставляется возможность узнавания в них себя.

Здесь же необходимо отметить и такой фрейм, как «трудовая династия - совесть производства». Призывы к борьбе против сложившейся неверной системы, актуализация тезиса: «жить не по циркулярам, а по совести». Показательна сцена, в которой старый потомственный рабочий Матвей Журбин критикует начальство за роскошь в быту. Здесь отчетливо показано противопоставление трудового класса бюрократическому начальству: «Вот ты

\footnotetext{
${ }^{1}$ Большая семья. Доступ: https://www.kinopoisk.ru/film/46175/ (проверено 19.10.2021).
} 
себе два автомобиля завел: на одном сам, на другом жена по магазинам... нехорошо это... [пример про Ленина и парикмахерскую]. А тебя парикмахерша в кабинете бреет» (Матвей Журбин, 1:04:14).

Как уже отмечалось, династийность в интеллигентных профессиях особо не приветствовалась, однако в качестве исключения необходимо отметить презентацию династийности в медицинской сфере, но с обязательной оговоркой - врач в сельской местности, где наблюдается кадровый голод. Ярким примером является фильм «Здравствуйте, доктор!». По сюжету фильма молодой талантливый хирург Александр приезжает в отпуск в село, где местный доктор Трофим Зубцов обращается к нему за помощью. Весь свой отпуск Александр ведет прием пациентов, т.к. хирурга в селе нет. Но сюжет о династийности в фильме не является центральным, а используется для усиления эффекта гордости за свою профессию со стороны сельского врача Трофима Зубцова: «Вы просто не знаете, что такое сельский врач. Ведь это универсал! В нашей семье сушествовала традиция - идти в народ к людям, вооружившись знаниями, конечно, для того чтобы быть полезным людям. Вот! Это мой дед. Сто лет тому назад пришел сюда в грязь, в неустройство... На триста верст кругом не то что врача, фельдшера нет! Вы понимаете? Представьте себе, дворянин, порвал с отцом, пришел сюда, женился на крестьянке... А вот это мой отец, он земский врач, а вот это я, еще до поступления в университет, и вот это я (показывает на университетское фото), и вот это я (показывает на себя)» (22:56).

Прогностический фрейм. Рассматривая проблематику прогностических фреймов в советском кинематографе, следует заметить, что формирование прогноза на будущее никогда не являлась приоритетной задачей для режиссеров и сценаристов «производственного» кино. Производственный кинематограф, в т.ч. и кинематограф, затрагивавший тематику семейных трудовых династий, исходил, как правило, из принципа «здесь и сейчас», сосредоточиваясь на рассмотрении конкретной проблемы/ситуации, после разрешения которой (в той или иной степени) дальнейшее будущее не имело интереса. В целом можно выделить два типа прогностических фреймов, имеющих четкую хронологическую границу.

1. «Оптимистичный фрейм». Характерен для кинематографа 30-60-х гг. XX в. Какправило, возникающие перед героями проблемы и сложности разрешаются, налаживается линия четкого взаимодействия, в конечном итоге приводящая как к производственным победам, так и триумфам на фронте личной жизни. Негативные герои либо подвергаются перевоспитанию и занимают достойное место в рядах творцов светлого будущего, либо оказываются разоблаченными и подвергаются наказанию. Этот вектор, заложенный еще в 30-е гг, продолжается в 40-е гг. («Светлый путь», реж. Г. Александров, 1940; «Свинарка и пастух», реж. И. Пырьев, 1941; «Кубанские казаки», реж. И. Пырьев, 1949) и получает распространение в фильмах 50-х и 60-х гг. («Большая семья»; «Добровольцы»). Разница заключалась в том, что если на первом этапе становления отечественного кинематографа в роли старшего наставника выступал, как правило, мудрый коммунист - бригадир, скорее всего не связанный родственными отношениями с главным героем, то в 50-60-е гг. такими героями становились представители старшего поколения, непосредственно связанные узами родства с героем. Так, например, в фильме «Добровольцы» (просмотр - 26,6 млн чел.) $)^{1}$ показан положительный пример отца (Кайтанов), который перенимает его сын Слава, комсомолец, активист. В свой день рождения он не приходит вовремя: «Ушел в ночную смену, обещал пораньше вернуться и исчез на все

\footnotetext{
1 Добровольцы. Доступ: https://www.kinopoisk.ru/film/44239/ (проверено 19.10.2021).
} 
воскресенье... Даже на свой день рождения не является! - Есть с кого пример брать. Папа - вот тут клятву давал, что из дома больше ни на шаг (находится в этом момент в другом городе на масштабном социалистическом строительстве), <...> хорошо хоть на день рождения сына телеграмму прислал...» (из диалога Лели, жены Кайтанова и матери Славы, и Славки Уфимцева, 1:18:48). В момент диалога вбегает Слава Кайтанов, он и его бригада берут обязательство отработать в шахте в помощь Японии, где случилось землетрясение, еще одну смену, и убегает. После его ухода становится ясно, что такая ситуация самоотверженности - норма, т.к. хорошим примером является отец: «Видали? Кайтанов! - Нормально!» (1:20:22), для которого преданность делу, своей стране, самоотверженность, начиная с молодости и по настоящее время, является нормативной моделью поведения.

2. «Пессимистичный фрейм», 70-80-е гг. Вызван общим контекстом идеологического и социального состояния общества в тех исторических условиях, которые обозначены сейчас как «период застоя», разочарованием интеллигенции в результатах «оттепели», понимание невозможности преобразования административно-командной системы. Трудовая династийность уступает место «аристократии номенклатуры» («Гараж», реж. Э. Рязанов, 1979; «Курьер», реж. К. Шахназаров, 1986). В фильме «Гараж» показана ситуация включения в члены гаражного кооператива сына товарища Милосердова без соблюдения процедуры голосования по одобрению данной кандидатуры со стороны других членов гаражного кооператива. «Как вы смеете называть товарища Милосердова - какой-то там и никакой?» (Аникеева - член правления, 20:04); «да что это делается, а? Сынка большого начальника по блату впихнули, а меня, работника института, выпихнули!» (Фетисов, 20:33). Однако на защиту исключенного из кооператива члена коллектив не становится, происходит оправдание включения сына товарища Милосердова другими членами кооператива: «После принятия его сына строительство пошло другими темпами» (Карпухин, 21:50), и возмущение утихает.

Особняком стоит рассмотрение проблематики трудовой династийности в отечественных фильмах, посвященных силовым структурам, таким как армия и органы охраны правопорядка. Важным фактором, обусловившим коренное различие демонстрации династийных порядков в этих сферах и общегражданских, стало то, что такие фильмы, как правило, производились по заказу и при консультации вышеуказанных структур. В данных фильмах все фреймы имеют сугубо положительный окрас, а династийность, будь то фронтовая (капитан Енакиев и Ваня Солнцев в фильме «Сын полка», реж. Г. Кузнецов, 1981), либо профессиональная (семья Алексея Трофимова в фильме «Офицеры»; семья Беловых в сериале «Государственная граница», 1980-1988 гг.); семья Николая Кондратьева - сотрудников органов охраны правопорядка в сериале «Рожденная революцией»), показаны как дело чести и геройства. Младшее поколение усваивает ценности и ориентиры практически с рождения. Одним из традиционных сюжетных ходов является гибель старшего представителя династии и преемственность молодого представителя семьи родительской позиции, причем в основном ребенок-последователь в итоге превосходит достижения отца. Диагностический фрейм в лентах на заданную тематику практически отсутствует, а мотивационный и прогностический представлены как преподнесение зрителю достойной модели жизненного пути, которому можно и до́лжно следовать. Для героических профессиональных групп, групп с риском для жизни, выполняющих важнейшую социальную функцию - обеспечение внутренней либо внешней безопасности страны, династийность в фильмах выступала как норма. 
На основании сказанного выше можно сделать следующие выводы.

В советском производственном кино, где в том или ином виде отражалась тематика профессиональной династийности, можно выделить следующие центральные фреймы и их содержательные категории:

1) диагностический центральный фрейм (то или иное явление определялось как проблема, которую надо продемонстрировать населению и показать пути еe решения), представленный следующими категориями проблем: «личное vs общественное» (существует на протяжении всей истории советского кинематографа), «династийность и непотизм» (70-80-е гг.);

2) мотивационный центральный фрейм (посыл фильма в конечном итоге должен был сформировать у зрителя нужный психоэмоциональный настрой, дать ему примеры/образцы поведения) представлен такой категорией, как «гордость за свой труд и продолжение семейной династийной традиции, трудовые династии как “совесть производства” ( $30-50-е$ гг.);

3) прогностический центральный фрейм, который представлен двумя сюжетными категориями: «оптимистический», т.е. с позитивной траекторией возможного будущего развития (30-60-е гг.), и «пессимистический» $(70-80$-е гг.).

Прослеживается более выраженная позитивность коннотаций фреймов в репрезентации династий рабочих и представителей героических профессий (военные, милиция), в то время как династийность нерабочих профессий имеет нейтральные или негативные коннотации, что было обусловлено идеологическими задачами.

Статья подготовлена при поддержке Российского научного фонда, проект № 19-18-00320.

\section{Список литературы}

Актуальные вопросы массовой информации и политических коммуникаций: коллективная монография (под общ. ред. А.В. Атанесяна, И.А. Румачик). 2017. Ереван: Изд-во ЕГУ. 214 с.

Гольбрайх В.Б. 2013. Экологический конфликт в местной прессе. - Журнал социологии и социальной антропологии. № 3. С. 63-80.

Горшков М.К. 2011. Российское общество как оно есть. М.: Новый хронограф. $672 \mathrm{c}$.

Здравомыслова Е., Темкина А. 2002. Кризис маскулинности в позднесоветском дискурсе. - O муже $(N)$ ственности: сборник статей (сост. С. Ушакин). М.: Новое литературное обозрение. 720 с.

Макаренко А.С. Лекции о воспитании детей. Общие условия семейного воспитания. Доступ: https://www.litmir.me/br/?b=577833\&p=1 (проверено 26.11.2021).

Социальная мобильность в России: поколенческий аспект (отв. ред. В.В. Семенова, М.Ф. Черныш, А.В. Ваньке). 2017. М.: Изд-во ИС РАН. 384 с.

Терентьев А.А. 2003. Социальная структура российского общества: прошлое и настоящее. Нижний Новгород: Изд-во НГПУ. 70 с.

Ткач O. 2003. Патриархат по-советски, или Большая семья на большом экране. - Гендерные отношения в современной России: исследования 90-х годов (под ред. И. Тартаковской, Л. Попковой). Самара: Изд-во СамГУ. С. 294-316.

Федоров А.В. 2016. Кинематограф в зеркале советской и российской кинокритики. М.: МОО «Информация для всех». 228 с.

Храмов В.Б. 2009. Советское кино как феномен советской культуры. - Теория и практика общественного развития. Вып. 2. С. 183-200.

Черняева К.О., Сорокина Н.В. 2019. Дискурс профессиональных династий 
в советском медиапространстве (на примере газеты «Правда» 1960-1970 гг.). Гуманитарий Юга России. № 6. С. 254-267.

Hilgatner S., Bosk C. 1988. The Rise and Fall of Social Problems: A Public Arenas Model. - American Journal of Sociology. Vol. 94. Is. 1. P. 53-78.

Nelson T., Oxley Z., Clawson R. 1997. Toward a Psychology of Framing Effects. Political Behavior. Vol. 19. Is. 3. P. 221-246.

Scheufele D.A., Tewksbury D. 2007. Framing, Agenda Setting, and Priming: The Evolution of Three Media Effects Models. - Journal of Communication. Vol. 57. P. 9-20.

POSUKHOVA Oksana Yur'evna, Cand.Sci. (Soc.), Associate Professor of the Chair of Regional Studies and Euroasian Researches, Institute of Sociology and Regional Studies, South Federal University (160 Pushkinskaya St, Rostov-on-Don, Russia,344006; belloks@yandex.ru)

CHELYSHEV Sergey Mikhailovich, Intern Researcher, Institute of Sociology and Regional Studies, South Federal University(160 Pushkinskaya St, Rostov-on-Don, Russia, 344006; msyeserj@mail.ru)

\title{
DYNASTICITY AND FRAMES OF THE SOVIET CINEMA DISCOURSE
}

\begin{abstract}
The article is devoted to the consideration of the institutional conditions of the representation of professional dynasties in the film discourse and the analysis of the substantial transformation of the Soviet film discourse about professional dynasties. Cinema is considered in the work as one of the public arenas in which a particular social problem is presented by audiovisual means. To analyze the Soviet cinema discourse, the authors use the frame analysis. In the analysis of movie frames, according to the concept of $D$. Snow and $R$. Benford, it is advisable to allocate three central frames: diagnostic, prognostic and motivational ones. The empirical basis of the study was seven Soviet films, in which the phenomenon of dynasticity is present to varying degrees. The authors establish that the diagnostic central frame is represented by such categories as "personal vs public", "dynastic and nepotism»; motivational one - "pride in your work and the continuation of the family dynastic tradition, labor dynasties as the "conscience of production". The prognostic central frame is represented by two plot categories: "optimistic" (30s-60s) and "pessimistic» (70s-80s). The designation of meaningful categories of frames allowed fixing a more pronounced positivity of frame connotations in the representation of dynasties of workers and heroic professions (military), while the dynasticity of non-working professions has neutral or negative connotations.
\end{abstract}

Keywords: dynasties, profession, frame, film discourse, Soviet cinema 